\title{
The Development and Practice of Small Hydropower Clean Development Mechanism Projects in China
}

Liu Heng and Hu Xiaobo

\begin{abstract}
This paper generally describes the background of global hydropower CDM projects and the development of Small Hydropower (SHP) CDM projects in China. It analyses the features of China SHP CDM projects, and summarize their prospect and future challenges.
\end{abstract}

Key words: Small Hydropower (SHP), Clean Development Mechanisms (CDM) Development and Practice, China

\section{The Kyoto Protocol and Clean Development Mechanisms (CDM)}

According to the UN Framework Convention on Climate Change (UNFCCC) and the Kyoto Protocol (KP), the purpose of which is to decrease emissions of Greenhouse Gas (GHG) as well as attain legally binding GHG reduction targets during the period 2008 to 2012 for committed developed countries, three special 'Flexibility Mechanisms'-namely, the Joint Implementation (JI), the Clean Development Mechanisms (CDM), and Emission Trading (ET), are established to be implemented, respectively. Among the three mechanisms, the Clean Development Mechanism provides a means for win-win project cooperation through CDM between developed and developing countries. By this means, on one hand, it decreases the cost of emission reduction in developed countries and achieves its target of emission reduction. On the other hand, developing countries benefit by acquiring capital and technologies for sustainable development. It is estimated that the average cost of emission reduction in developed countries is approximately $100 \mathrm{USD} /$ ton, while it is only $10 \mathrm{USD} /$ ton approximately in developing countries. It is such a huge gap on emission reduction that promotes the development of CDM by leaps and bounds, and enables CDM as one of the most active carbon financing mechanisms up to the present.

Since the Kyoto Protocol officially came into force on 16 February, 2005, CDM has been developed dramatically in China. By 1st July, 2007, a total of 2,142 CDM projects had already been developed in China. It is expected the total reduced emission of $\mathrm{CO} 2$ will reach to 1.5 billion tons by the year 2012, and the developed CDM projects as well as the estimated emission reduction in China will count for $40 \%$ and $54 \%$ of the global CDM market, respectively. Notably, hydropower has the biggest share of CDM market in China with 934 projects accounting for $44 \%$ of CDM projects. Besides, the registered Chinese SHP CDM projects rank the first in the World. The SHP industry in China is abundant with huge resources on carbon emission, and thus SHP carbon trading has broad marketing prospect in China.

On 12 October, 2005, the Chinese government issued Regulations on the Operation and Management of Clean Development Mechanism Project. The national
$\mathrm{CDM}$ verification council, functioning as the agency for verification and decision-making on CDM projects, is composed of National Development and Reform Commission, Ministry of Technology, Ministry of Foreign Affairs, Ministry of Environmental Protection, China Meteorological Administration, Ministry of Finance, and Ministry of Agriculture. The National Development and Reform Commission is the designated as the national authority on CDM projects implemented by Chinese government, and the Department of Climate Change, under National Development and Reform Commission, is responsible for project implementation. In its Regulations on the Operation and Management of Clean Development Mechanism Projects, the Chinese government prescribes that the key fields of CDM projects will focus on improving energy efficiency, developing new energy and renewable energy, as well as recycling methane and coal bed methane. Up to now, small hydropower, biomass energy, wind energy and rubbish recycling are the main potential resources for $\mathrm{CDM}$ project development in the new energy and renewable energy fields. Figure 1 indicates the complete flow of CDM project development.

\section{SHP CDM Project Development and Prac- tice in China \\ Hydropower Projects: The Important the CDM Type in the World}

Hydropower projects are the most common CDM type. For potential buyers, hydropower projects are comparatively stable and technically proven. They have clear advantages compared with other types of projects, and thus are popular with funders and governments as well. The RIO Blanco project with a totally installed capacity of $5 \mathrm{MW}$ in Honduras, which was registered in January 2005 with a reduced emission of 17,800 tons CER (Certified Emission Reduction)/year, is the first hydropower CDM project in the world.

By July 2010, there are 5,312 CDM projects under development in the world, among which 1,454 are hydropower projects, accounting for $27 \%$ of the all CDM types. A total of $743 \mathrm{CDM}$ projects receive CER, among which 166 are hydropower projects, accounting for 22\% of all CDM types. Before the end of 2012, approximately 


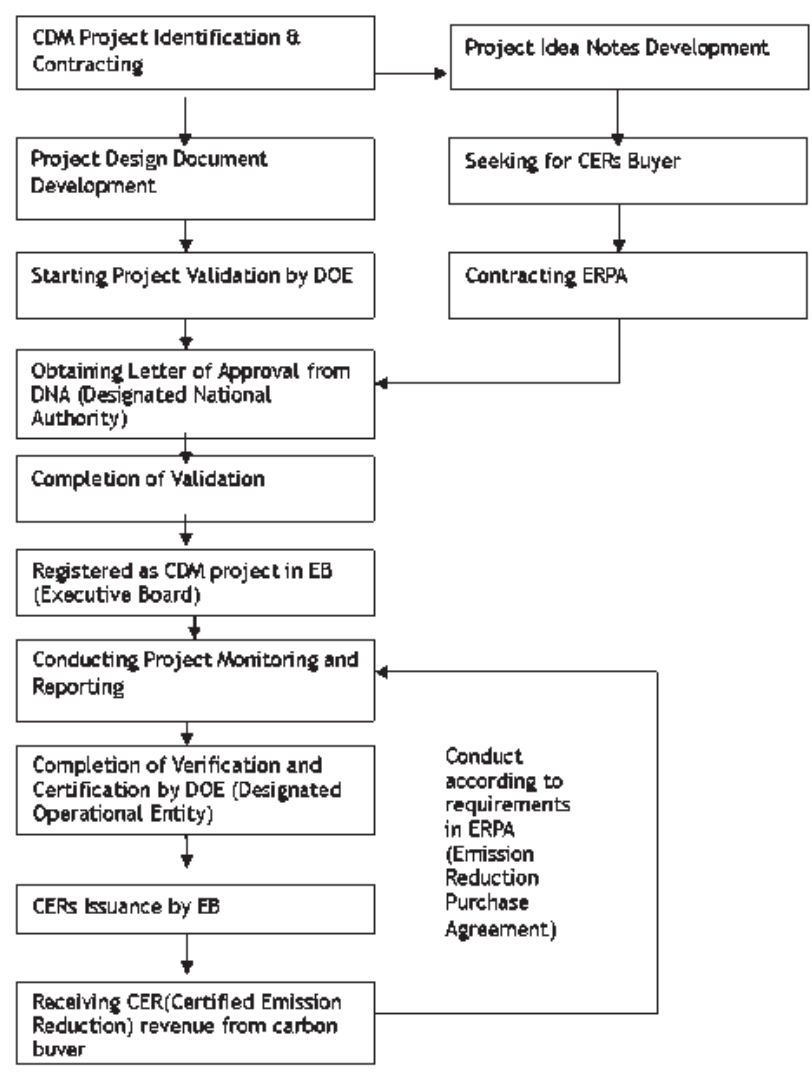

Figure 1. Flow Chart of CDM Project Development in China

$20 \%$ of the issued carbon CERs will be from hydropower projects. By July 2010, aggregated 20,069,000 tons of carbon CERs have been issued for hydropower projects by the United Nations. On Table 1, which indicates the hydropower CDM projects under development in the world, it can be seen that China, India and Brazil rank the top three on number of hydropower CDM projects and total installed capacities.

\section{Development of SHP CDM in China}

SHP is a renewable energy with advantages of proven technology, convenient maintenance and low operation costs. SHP projects have minimal impact on the environment through effective control when under construction. In addition, SHP projects can improve the local environment once completed in most cases, satisfying the demand for harmonious co-existence of hydropower development and sustainable social development and environmental protection. Therefore, SHPs achieve significant development in China.

Up to now, more than 45,000 SHP stations have been constructed in China with total capacity of over 55 million $\mathrm{kW}$, providing clean renewable electric power to a rural population of over 300 million nationwide. Some SHP projects, however, are less attractive for investment and can not be constructed due to their small scale and/or rural development orientation. Fortunately, it is $\mathrm{CDM}$ that provides the possible means to such kinds of

\begin{tabular}{|l|r|r|}
\hline $\begin{array}{l}\text { Countries } \\
\text { Projects }\end{array}$ & $\begin{array}{c}\text { Number of } \\
\text { Capacity ( MW ) }\end{array}$ & Installed \\
\hline P. R. China & 934 & 32,258 \\
\hline India & 152 & 6,409 \\
\hline Brazil & 85 & 3,974 \\
\hline Chile & 19 & 575 \\
\hline Peru & 23 & 1,402 \\
\hline Panama & 14 & 249 \\
\hline Ecuador & 12 & 658 \\
\hline Viet Nam & 12 & 328 \\
\hline Honduras & 13 & 122 \\
\hline Sri Lanka & 9 & 62 \\
\hline South Korea & 13 & $\mathbf{1 1 8}$ \\
\hline Guatemala & 9 & $\mathbf{2 7 0}$ \\
\hline Bhutan & 3 & $\mathbf{1 , 1 3 4}$ \\
\hline Others & $\mathbf{1 5 6}$ & 5,486 \\
\hline Total & $\mathbf{1 , 4 5 4}$ & $\mathbf{5 3 , 0 4 4}$ \\
\hline
\end{tabular}

Table 1. Hydropower CDM Projects under Development in the World (by July $1^{\text {st }}, 2010$ )

SHP projects to be financed and developed. The Yuzaikou Project, for example, was successfully registered on December 18, 2005, as the first hydropower CDM project in China developed by the International Center on Small Hydro Power. The success of this project greatly encourages and strengthens investors' confidence in Chinese hydropower CDM projects. In Figure 2 the annual growing tendency of successfully registered Chinese hydropower CDM projects at the UN in recent 5 years can be seen.

According to the data from the Chinese Climate Change Network, there has been 2537 CDM projects approved by the National Development and Reform Commission by May 12, 2010, among which 1106 are hydropower projects, accounting for $44 \%$ of all the approved. In the meantime, according to the data from the UN Climate Change Executive Commission Network, 883 Chinese CDM projects have been successfully registered at UN by July 2010, among which 434 are hydropower CDM projects, accounting for nearly $50 \%$ of all the registered.

\section{Features of Chinese SHP CDM Projects}

Based on the analysis of 434 registered Chinese hydropower CDM projects, it can be concluded that development of Chinese hydropower CDM has the following

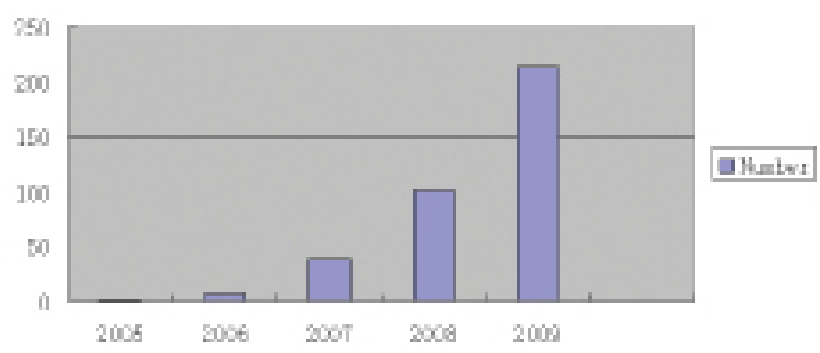

Figure 2. Registered Chinese Hydropower CDM Projects at UN (from the years 2005-2009) 
features: large quantity and extensive location of SHP $\mathrm{CDM}$ projects, and dominance of run-off SHP project.

\section{SHP is the Mainstay of CDM Development}

According to the CDM rules, hydropower CDM projects can be adopted with two methodologies, namely Small Scaled Grid Connected Renewable Electricity Generation of less than $15 \mathrm{MW}$, and Grid Connected Renewable Electricity Generation (ACM 0002; Approved Consolidated Methodology) which can be adopted for conventional hydropower projects with capacity of over 15 MW. Notably, for those SHP projects with capacity of less than $15 \mathrm{MW}$, the simplified procedures of small scaled CDM projects can be adopted. It is widely applied due to its advantages of short application period, low transaction fees and high success rate of registration. Besides, large hydropower CDM projects are frequently questioned and even rejected on the global market, particularly the European market. European Union controls the CERs produced from the hydropower CDM projects with capacity of over 20 MW out of the EU Emission Trading System. This is causing negative effect on global demand on large hydropower CDM project to large extend.

Based on the definition of SHP (less then $50 \mathrm{MW}$ ) in China, registered SHP CDM projects account for $80 \%$ of all the registered hydropower CDM projects (see Figure 3).

\section{Dominance of Run-off Hydropower CDM Project} In order to decrease the negative impact on the environment by hydropower projects, particularly the reservoir type, and according to relevant methodology, it is best to choose unadjustable run-off hydropower stations for application of hydropower CDM projects. If a reservoir is newly added into hydropower CDM projects, the Power Density (PD) must be proved more than 4 $\mathrm{W} / \mathrm{m}^{2}$ (watts per sq. meter). Based on the analysis of registered Chinese hydropower CDM projects, most of projects are run-off hydropower stations (about 64\%). Newly constructed power stations with reservoirs are required having no negative impact on the environment including resettlers and inundated areas.

\section{Extensive Location of Registered Chinese $\mathrm{Hy}$ - dropower CDM Project}

By July 1st, 2010, the 434 registered Chinese hydropower CDM projects at U.N. FCCC CDM EB are located in 21 provinces or cities. The provinces of Yunnan, $\mathrm{Si}-$

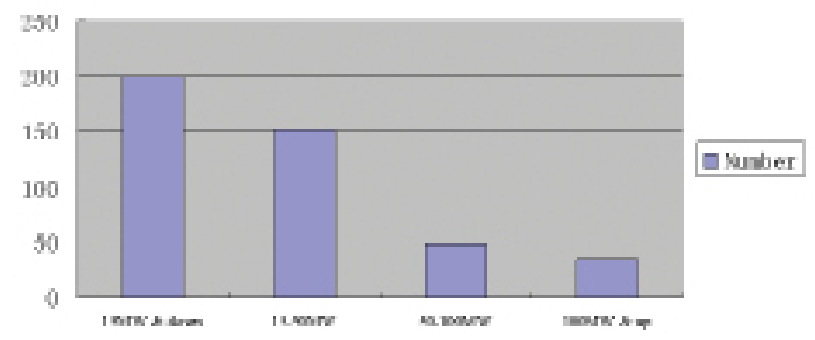

Figure 3 Distribution of Installed Capacity of Chinese Registered Hydropower CDM Projects chuan, Hunan, Gansu and Guizhou are the top five with 300 projects accounting for $69 \%$ of all registered. Thus it can be concluded that apart from the regions with abundant hydro resources, potential hydropower CDM projects are mainly located in poverty-stricken regions (low tariff), regions with bad geographical condition (high investment per $\mathrm{kW}$ ), and regions with bad hydrological condition (low output).

\section{Prospect and Challenge of Chinese SHP CDM Project}

\section{Broad Prospect of SHP CDM Project}

Compared with other technologies, SHP project has advantages for application of CDM funds as renewable energy. It complies with important requirements of targets of the Kyoto Protocol and Clean Development Mechanism as SHP is a renewable energy which has minimal impacts on environment and helps for promotion of sustainable development. Some SHP projects are less attractive for private investment and can not be constructed due to its small scale and /or rural development orientation, while CDM provides developers of such kind of SHP projects with opportunities of obtaining financial support. Generally speaking, small hydropower stations are small scaled and local communities oriented, bringing about direct benefits for environmental, social and economic development. Compared with large hydropower projects, SHP causes minimal debates on environment, enabling its approval of renewable energy project much easier.

China is abundant of the richest SHP resources in the world with potential of $128 \mathrm{GW}$ located extensively in 1,715 counties (municipality) in 30 provinces, autonomous regions and the municipalities directly under the central Government. Up to present, the total capacity of 20 million $\mathrm{kW}$ of SHP projects is under construction in China with annual added installed capacity of over 3,000 MW. Therefore, SHP has broad marketing prospect for cooperation of CDM projects. In a word, the great potential and its developed capacity of Chinese SHPs as well as the energetically support from governments facilitate the broad prospects of SHP development under CDM projects.

\section{Challenges of SHP CDM Project}

The development of SHP projects under CDM is also faced with challenges both from the common and unique issues in China. For example, it is a big challenge to prove the additionality of SHP CDM projects, particularly in the fact of well-developed SHPs. Besides, Chinese SHP technology and know-how develop all-round perfectly, creating leading SHP technologies, plenty of experiences and lots of experts. Due to the importance of technology transfer, which is stressed in China, the government encourages more advanced technologies such as automatic systems applied in SHP 
projects. In this case, it is much more difficult for developers of CDM projects to prove the general obstacles on technology and development of SHP.

From the micro viewpoint, SHP CDM projects have the following possible uncertainties in development:

- The final approval and registration of CDM projects are decided by the UN and its designated verification agencies complying with international rules.

- $\mathrm{CDM}$ is a flexible international cooperating mechanism with features of marketing economy, complying with market rules and thus must be operated according to the marketing regulations.

- CERs produced from projects are invisible goods with much uncertainties in future.

- $\mathrm{CDM}$ trading requires national administrative permissions of both buyer and seller, and it is impacted by the administrative intervention to large extent. There are many uncontrollable factors such as the change of conventions and related national policies, thus the CDM trading has uncontrollable risks.

From the macro viewpoint, there are also many challenges from an international political perspective, such as the following:

- The progress of political negotiations on international climate change.

- Whether the CER can be accepted continuously by the European Union (EU) and brought into the EU Emission Trading System.

- Whether the USA has a growing demands for CDM (at present, only some American enterprises have volunteered to reduce emissions through a variety of means including participation in CDM market; provided that America has a growing demand for $\mathrm{CDM}$, there must be mandatory legislative requirements from the state or senate).

- Whether the requirements on Emission Reduction of the EU and post Kyoto Protocol will be much stricter in future.

- Whether the continuous economic recovery is possible.

The development of Chinese SHP CDMs is still in a primary stage at present, and low status of participation on the international carbon market embodies the three following aspects:

1. The SHP CDM carbon market is in disorder with a lack of regulation and monitoring. There are few channels for communication between suppliers and buyers. Both information and prices are not open. The buyers, intermediary agents and developers lack standards and qualifications. The success rate of registration of SHP CEM project is still low.

2. The modality of participation in CDM of SHP enterprises is very limited, relying on over-the-counter transactions between companies in most cases, which is focused on cheap primary markets and lack of pricing mechanism.

3. It is urgent for hydropower administrative departments to strengthen participating promotion of CDM. Though more than 3,00oMW of SHPs are put into production annually, the success of CDM development counts only for approximately $10 \%$. Thus from the macro viewpoint, there is still large potential for benefits of SHP industry.

China, the country which possesses $50 \%$ of the SHP installed capacity in the world, urgently needs to develop management policy on SHP CDM projects and research strategies as well to suggest the promotion of SHP CDM and the regulation of project management in order to:

- Strengthen the competitiveness of Chinese SHP CDM project in global carbon market.

- Deepen the understanding and application of international CDM rules and profit modality for SHP enterprises.

- Improve the integrated capacity building of SHP industry.

- Stipulate the strategy and planning for sustainable development of Chinese SHP industry.

- Improve the low status of Chinese SHP CDM in the international carbon market and its formed value chains.

- Take the lead initiative of the global carbon market gradually.

\section{Brief Introduction of Typical Chinese SHP CDM Project}

The International Center on Small Hydro Power (ICSHP) is one of the earliest domestic agencies to enter the fields of research and exploitation on CDM trading. IC-SHP, the first China-based international organization, is a subsidiary directly under the Ministry of Water Resources (MWR) and is consultative agency under the United Nations Industrial Development Organization (UNIDO). After 16 years of development the IC-SHP has established three sub-centers globally and four bases domestically with over 380 SHP members from home and abroad, taking the lead in exploring development of SHP CDM projects.

In 2001, the IC-SHP carried out pilot research on SHP CDM projects in Zhangye, Gansu Province. The project was accepted by the global bidding of $\mathrm{CO}_{2}$ CERs from the Netherland government, and the Department of Climate Change under National Development and Reform Commission (NDRC) approved it, directly promoting the investment on Xiaogushan CDM project in Zhangye, Gansu province by the World Bank. In 2003, the ICSHP compiled the design report of CDM projects based on the practical research of the selected Yuzikou Project located at the SHP base of IC-SHP in Chenzhou, Hunan Province. In October 2005, the verification council of CDM project under NDRC officially approved the Yuz- 
ikou Project and issued joint LoA (Letter of Approval) by four ministries. On December 18, 2005, the Yuzikou SHP CDM Project was registered officially at the CDM EB located in Bonn, Germany, being the first successfully registered Chinese SHP CDM project.

Located in Nandong, Rucheng County, Hunan Province with two sets of $7,500 \mathrm{~kW}$ Francis turbine generator units, the Yuzikou SHP station is a renewable generating source with zero emissions and the demonstration station of the IC-SHP. The station is downstream of Qijiang River, the primary tributary of Oujiang River and $30 \mathrm{~km}$ from Rucheng County. The project functions mainly for generation and sale of electric power to the Guangdong Provincial grid with integrated benefits of flood prevention and ecological governance after completion. The Yuzikou SHP station is expected to produce 66,000 MWh annual generation with 57,350 MWh of mean output, and 55,350 MWh of effective output annually for the grid.

Construction of the Yuzikou SHP station directly decreases the emission of green-house gas by thermal power stations, which are still under operation in China. By replacing the emission of green-house gas caused by the thermal power stations with fossil fuels in Guangdong Province, the reduced emission of $\mathrm{CO} 2$ of the Yuzikou SHP station is expected to be 40,480 tons annually. CDM brings about significant influence for the Yuzikou SHP Project. According to the trading contract of emission reduction, the income of $\mathrm{CO} 2$ emission reduction provides significant funds of approximately $11 \%$ of total investment for the project.

The Yuzikou SHP project was completed at the end of 2006. According to the contracted $\mathrm{CO} 2$ Emission Reduction Purchase Agreement (EDPA), the trading income of carbon emission reduction will provide about RMB (Chinese $¥) 10$ million of gratuitous assistance between 2008-2012 for the project since its generation in January 2007, and 242,880 tons of verified CO2 CERs realized by the project will be used for helping achieve the target of emission reduction of the Austrian government, realizing the win-win of both promoting sustainable development of developing countries and helping achieving target of emission reduction of developed countries.

Recently, the Qinan Project (18 MW) and Laopokou Project (24 MW) in Hunan Province are newly developed by the IC-SHP and registered at the UN with CER issuance. In addition, the Mae Project (24 MW) in Yunnan Province and several hydro CDM projects in Sichuan Province are proceeding successfully.

\section{Conclusions}

As an important approach of global emissions reduction and technology transfer, CDM under the UN Frame- work Convention on Climate Change (UNFCCC) can realize the win-win of both promoting sustainable development in developing countries and helping achieve target of emissions reduction of developed countries. The development of SHP CDM brings vigor to the SHP industry in China. However, there is still much space for promotion of transferring potential CDM market to practical CDM opportunities for China, which has an abundance of SHP resources and great potential. Good application of CDM in active participation of negotiating global climate change can maximally realize the sustainable development of the Chinese national economy and environment, contributing in the meantime to reduce global climate change.

Prof. Dr. Liu Heng, is Director General of the International Center on Small Hydropower (IC-SHP) under auspices of UNIDO, and Vice President of China's Nanjing Hydraulic Research Institute. He graduated from Hohai University of China and UNESCO-IHE of The Netherlands. He is senior engineer and has being engaged in hydrology and water resources research since 1981. He is currently Chairman of the Regional Steering Committee for International Hydrological Program of UNESCO in Southeast Asia and the Pacific. Prof. Liu has published over 70 papers in national and international scientific journals.

Corresponding address: hliu@china.com

Ms Hu has been working for the IC-SHP for over 10 years. She has a sound technical and engineering knowledge and understanding of small hydropower systems and practical experience in SHP relevant project application, implementation and management for technical cooperation, training and information exchange, fundraising, capacity building, etc. She has successfully completed the first registered hydropower CDM project in China in December 2005 and has done research on carbon financing for small hydropower as well.

Corresponding address: linda_hic@163.com

\section{References}

CCChina, n.d., (homepage of China Climate Change; in Chinese); URL: cdm.cchina.gov.cn/web/index. asp.

Fenhann, Joergen, UNEP Risoe CDM/JI Pipeline Analysis and Database (July 1, 2010), UNEP RISØ Centre; URL: cdmpipeline.org.

Kossoy, Alexandre and Philippe Ambrosi, 2010, State and Trends of the Carbon Market, Washington DC: World Bank, Development Economics Research Group.

Mariyappan, Jason, Simon Taylor, Joanna Church and John Green, 2004, CDM Project to Stimulate the Market for Family Hydro for Low Income Families, Final Technical Report, Hampshire, UK: IT Power. 
The International Rivers Network, and CDM Watch, 2003, The Good, the Bad, and the Dammed Ugly: Status Note on Large Hydro and the Clean Development Mechanism; URL: www.cdmwatch.org/ files/Daming\%20CDM\%20update.pdf.

UNFCCC, 2002, Simplified Modalities and Procedures for Small-Scale Clean Development Mechanism Project Activities: Further Clarifications on Defini- tions of Eligible Activities, UNFCCC/CP/2002/7/ Add.3 (U.N. Framework Convention on Climate Change), pp.18-19; URL: cdm.unfccc.int/pac/Reference/Documents/AnnexII/English/annexII.pdf.

World Bank and National Clean Development Mechanism Center and Energy Research Institute of the China (NDRC), May 2010, Clean Development Mechanism in China (conference edition).

\section{CALENDAR OF HYDRO POWER EVENTS}

o1-12 Feb 2011, Small Hydropower Development, Location: Roorkee, India. More info: http://ahec.org. in

21 Feb- 23 April 2011, Sustainable Hydropower Postgraduate Course, Location: Vienna. More info: http://www.esha.be/index.php?id=153

3-5 March, 2011 Speedy Development of Hydropower in Developing Countries: Issues and Challenges, Location: Kathmandu, Nepal; Contact Dr. SN Misra, e mail:sumit@info.com.np

March 2011, Training on Micro/Mini Hydropower in Design/Construction Supervision (national level), Location: Kathmandu, Nepal. More info: http://www. wecan.org.np/

21 -22 March 2011, Sustainable Hydropower Asia 2011, Location: Vietnam. More info: Email: ruby. pham@abf-asia.com, Website: http://www.abf-asia. com

13-15 April 2011, Small Hydro 2011, Location: Vancouver, British Columbia, Canada, More info: Website: http://www.arena-international.com/smallhydro, Email: EmanEl-Labban@arena-international.com

5-7 May 2011, HydroVision India 2011, Location: New Delhi, India, More info: http://www.hydropowerindia.com

23-26 May 2011, Hidroenergia 2011, Location: Wroclaw, Poland, More info: Website: http://www.esha.be Email: info@esha.be

14-17 June 2011, International Hydropower Asso- ciation (IHA) 2011 World Congress on Advancing Sustainable Hydropower, Location: Iguassu Falls, Brazil, More info: http://www.hydropower.org/events/ ev_211832183234.html

20 June 2011, APEMEC 2011 (Small Hydro Trade Fair \& Conference), Location: Santiago, Chile; More info: Website: http://www.apemec.cl; Email: info@ apemec.cl

20-24 June 2011, Meeting the Challenges of Financing Hydropower Projects in Liberalized Markets, Location: Oslo, Norway. More Info: www.ich.no; Application deadline: 31 March 2011

19 - 22 July, 2011, Clean Energy Hydrovision International 2011, Location: Sacramento Convention Center, Sacramento, CA USA. More info: http://www. hydroevent.com

22 August-9 September 2011, Hydropower Financing, and Project Economy; Management of Environmental and Social Aspects of Hydropower Development, Location: Trondheim, Norway. More Info: www.ich.no; Application deadline: 8 April 2011

5-7 September 2011, 3rd Australasian Hydro Power Conference, Location: Queenstown, New Zealand. More info: Website: http://www.hydroconference. co.nz/ Email: schurinkj@mace-eng.co.nz

3-8 October 2011, The process of Social Impact Assessment Location: Trondheim, Norway. More Info: www.ich.no; Application deadline: 15 June 2011

\section{...Continued from page 74}

\section{Hydropower for Prosperity of Nepal}

Commentators:

Mr. Lila Nath Bhattarai, Director NEA commenting on the two papers, said that Hydropower sector has not been discouraging; NEA needs improvement in its management. The political parties have created conducive environment in Middle Bhotekoshi which should be exploited.

Mr. Guru P. Neupane is of the opinion that instead of electricity export, electricity consuming industries need

to be established in Nepal. The first priority should be strengthening the transmission line system. Since last 13 years, electricity produced from Khimti, Bhotekoshi, Middle Marsyandhi etc. could not be brought to Kathmandu due to non improvement in transmission line. Hence, this sector needs urgent improvement. The hydro sector needs to be tax free, electricity from storage project should be given good price and open up the Eastern sector. The private sector cannot produce electricity by paying $15 \%$ per annum interest to the Banks. Due to lack of Policy and Regulation, foreign investment is not coming in Nepal. 